\title{
O corpo cultivo da arte
}

\author{
Elizabeth Medeiros Pacheco, ${ }^{I \star \star}$ Thadeu Pinto Lobo, ${ }^{I I}$ \\ Gabriel Barbosa Gomes, "II Karina Junqueira Mata ${ }^{I I}$ \\ ${ }^{I}$ Universidade Federal Fluminense, Campos dos Goytacazes, RJ, Brasil \\ ${ }^{I I}$ Universidade Federal Fluminense, Niterói, RJ, Brasil
}

\begin{abstract}
Resumo
O capitalismo urbano midiático atual pervade as subjetividades, extraindo os afetos vitais, vetores de criação, através de máquinas semióticas que capturam a experiência da cooperação e inoculam nas vidas a autoexigência, a autosuficiência, a autoimaginação, na urdidura do mais individual dos mundos: o mundo sem si. Tal forma de vida se torna incubadeira das patologias do ânimo, com pregnância dos afetos de insuficiência, enquanto testemunhamos a expansão incessante das redes de solidão participada. Nesta constante convocação à dispersão pelo excesso de oferta e ânsia de velocidade, a constituição de experiência é cada vez mais precária e a mesma abundância que ora incita à demanda, pode também assombrar com o tédio. Nosso projeto O corpo sem álibi, pesquisa aberta ao convivio acadêmico da Universidade Federal Fluminense em Campos dos Goytacazes, consiste em compartilhar nossos corpos, seu poder de afetar e contrair memoria, apostando no corpo cultivo da arte como dispositivo micropolitico de resistência.
\end{abstract}

Palavras-chave: afetos; arte; corpo; experiência; resistência.

\section{The body-cultivation of the art}

\begin{abstract}
The current urban media capitalism pervade the subjectivities, extracting their vital affections, vectors of creation, through semiotics machines wich catch the experience of cooperation to inoculate in the lives the self demand, self sufficiency, self imagination, in a ploy of the most individualistic world that ever existed: the world without self. Such way of life form becomes incubator of many pathologies of the vitality, with the experience of inadequacy, while we testified the incessant expansion of the nets of announccing solitude. In this constant demand to the dispersion owing to the excess of the offer and wish of acceleration, the constitution of experience is more and more precarious and the same abundance that now it incites to the demand, it can also astonish with the boredom. Our research The body without alibi, wich is open to the academic conviviality of the Federal Fluminense University in Campos of Goytacazes, consists of sharing our bodies, their power to affect and to make memory, betting in the body-cultivation of the art as micropolitic resistance.
\end{abstract}

Keywords: affections; art; body; experience; resistance.

"Para homens dos quais toda naturalidade foi subtraida, todo gesto torna-se um destino" (AGAMBEN, 2015).

O capitalismo contemporâneo já não dispõe apenas de mecanismos de controle para afetar diretamente os corpos com meios que se justificam por suas finalidades. Os tempos mundanos cada vez mais nos assolam em seus ritmos de urgências e emergências, para as quais não cessam de reivindicar todos os álibis que se alinhem ao argumento da segurança que se impõe soberana. Não será que nosso ímpeto de imaginação e invenção vem sendo sequestrado em função da execução de programas que monitoram nossas vidas, segundo estratégias de sobrevida? Mas o que será constitutivo da experiência do valor da vida? As mudanças e transformações pelas quais uma vida torna singular o percurso de qualquer um parece terem-se esgotado nessa busca de estratégias de defesa - contra o inimigo de fora e contra o inimigo de dentro. Considere-se de fora o que estranho. Considere-se de dentro o que me estranha: Desejo. Mas não será o desejo este apetite de mundo? Mas que mundo ainda resiste perante este avassalador programa de nivelamento do real ao verificável? Como se constituem os parâmetros e os critérios com os quais os arautos da

\footnotetext{
^Endereço para correspondência: Universidade Federal Fluminense, Instituto de Ciências da Sociedade e Desenvolvimento Regional. Rua José do Patrocínio, 71. Centro - Campos dos Goytacazes, RJ - Brasil. CEP: 28010385. E-mail elizabethmp@id.uff.br, pintolobo@gmail.com, barbosagomesgabriel@gmail. com, karinajunqueira.s@gmail.com
}

eficácia pretendem esgotar a realidade com o que julgam conhecer através da ciência e/ou da técnica? Que desejo vingará perante esta convocação de nossa subjetividade ao país da Anestesia, drogados oficialmente para assegurar um real entorpecido por conveniências? Qual será o apelo que se aninha nestes usos se o desejo não visa satisfações, mas sim desejar? Como diferenciar o uso prescritivo da droga que se impõe, individualmente, medicinalmente, a populações de supostos perfis sintomáticos e/ou patológicos, de um outro uso de drogas que se compartilha como experimentação ou prenúncio de aventura? Esta imposição da funcionalidade que passa a convocar, em cada um de nós, os procedimentos de controle sobre nossos corpos e nossos hábitos e, simultaneamente, a insuflar a culpabilidade por nossas escolhas, aparece como sintoma da imensa ansiedade, do medo avassalador da experiência de falha, de incompletude, da imprevisibilidade da vida como devir. A vida que pulsa nas medulas sabe se esquivar, fugir, trair, gritar, lutar, mas pode não suportar a estase de apenas durar, como medida regrada de um tempo que apenas finda. Se nos afastarmos das experiências do simples viver que fazem o tempo sair do regime dos fins, podendo engendrar outros modos incitando o pensamento e a invenção, estaremos expropriados da graça e do vigor de nossos corpos. 
Guiada pelo regime estético, nossa pesquisa nos leva ao corpo como cultivo da arte, este impessoal poder do possível. A escolha deste nome, O Corpo sem álibi, se justifica por esta inevitável presença do corpo na cena de sua experiência psíquica, tornando indissociáveis a subjetividade do corpo e a corporeidade da subjetivação. O álibi, como figura jurídica, apresenta a evidente ausência do suspeito na cena da qual é acusado. Acontece ao corpo de não ter álibi, pois ele não pode se ausentar da cena da vida. A pesquisa se passa com alguns alunos da graduação em Psicologia (bolsistas e não bolsistas de desenvolvimento acadêmico) na intersecção entre o estudo de textos voltados à dimensão estética da experiência e certas práticas comuns a algumas terapias corporais, assim como à experimentação teatral. Através da interlocução entre a filosofia e a arte, nossa pesquisa propõe encontros de experimentação em grupo enquanto espaço de reapropriação da atividade relacional, pensando nossas práticas de modo a nos comprometermos com o fato de termos um corpo e de estarmos atentos aos vários regimes de sua afetabilidade, no corpo a corpo dos muitos corpos - humanos e inumanos - cultivando nossa escuta das emoções que vão constituindo a experiência de meio, como dimensão mais que pessoal, até impessoal ou transpessoal, criando memória de composição. O paradigma estético nos surpreende como invenção do real. As muitas práticas da pesquisa demonstram que ao adentrar o universo de outra pessoa, seus ambientes, seus meios, criamos novas significações e algo surge ali, algo acontece, tonalizando tudo o que se passa. Esse adentrar acontece fora do plano comunicacional, com olhos e poros bem abertos, "pisando devagar", deixando espaço para ser tocado pelas distâncias num entre-dois singular, que incita uma mutualidade, um estado de arte. Esse respeito com o espaço do outro resignifica a violência oculta e cotidiana da sociabilidade compulsória. Pesquisar essas questões tem nos proporcionado um olhar completamente atípico sobre a formação de psicólogo e suas aspirações científicas. Num momento em que a lógica empresarial e seu modelo de gestores impõe-se à educação, tornando o espaço acadêmico cada vez mais instrutivista, priorizando a adequação do estudante à sua devida inserção profissional como produto, em detrimento da vivência e da convivência em suas pesquisas no campo de sua problematização, consideramos que a experiência do cultivo do corpo e seus gestos afirma-se como plano estratégico de resistência.

O corpo que se constitui através das relações, perpassado por questões micropolíticas e macropolíticas comparece à cena de nosso cotidiano na universidade e convoca estratégias que possam enfrentar o problema ainda maior que a evasão estudantil, que é a precarização das condições de vida de estudantes, professores, técnicos e terceirizados, que compõem o ambiente acadêmico, seus afetos e suas práticas. Através das experimentações realizadas em nossos encontros, cultivamos a sensibilidade de um corpo que se desdobra para resistir às amarras do instituído, perante a arquitetura de poder que atravessa as relações institucionais que compartilhamos - enquanto discentes e docente - implicados no es- paço efetivo do nosso Campus universitário. Analisamos os modelos de relações que ali se produzem como corpo e como subjetividade, através do dispositivo de pequenas cenas para forum do Teatro do Oprimido e outras oficinas que permitem cartografar, com leitura semiótica, a distribuição dos espaços e as normas de seus usos, desde a arquitetura das salas dos prédios e containers, até a configuração dos corpos nas distintas situações de convivência tais como, nas reuniões, no auditório, na cantina, na tenda; também contamos com textos transdisciplinares, literatura e filmes. Através dos filmes como suporte aos estudos da semiótica, desenvolvemos o estudo dos signos e dos planos de composição dos corpos, a leitura dos gestos, que nos levam a considerar modos de vida que não são certos ou errados, mas outros.

Reverberando as palavras de Agamben (2015, p. 20), "a intelectualidade e o pensamento não são uma forma de vida ao lado de outras nas quais se articulam a vida e a produção social, mas são a potência unitária que constitui em forma-de-vida as múltiplas formas da vida". Nossas experiências na pesquisa permitem que façamos um recuo e pensemos o que é relevante em nosso tempo de formação, para além dos registros acadêmicos, méritos, títulos, coeficientes de rendimento, pois as modelizações impostas pelo instituído são certamente úteis à formação do social, mas a questão é a conveniência de sacrificar a saúde psíquica e a subjetividade para tornar-se útil. $\mathrm{O}$ que produz o conceito de utilidade vigente? Um trabalho acadêmico, por exemplo, não é prazeroso porque faz crescer minha lista de realizações, mas porque, além de me potencializar como aluno ou professor, constitui um plano de relações que afetam meus rumos como pessoa na implicação ética de minhas escolhas e dos meus gestos. Agamben apresenta os modos do fazer e do agir, identificando o gesto como um terceiro modo do agir que é propriamente sem álibi, pois um gesto se assume e esta condição apresenta a responsabilidade ética como o que é proprio ao humano. Citando-o: "Se o fazer é um meio em vista de um fim e a práxis é um fim sem meios, o gesto rompe a falsa alternativa entre fins e meios que paralisa a moral e apresenta meios que, como tais, se subtraem ao âmbito da medialidade, sem se tornarem, por isso, fins" (AGAMBEN, 2015, p. 59, grifo do autor).

Ao pensar numa perspectiva estética, não trataremos da estética do belo ou da Estética como estudo da arte, mas de uma estética das sensações, ou uma estética dos poros, que respiram ou sufocam, tratando das imagens que chocam, das imagens que afetam das mais diversas formas, abrindo o atual para deixar vir o virtual. O que temos em vista é pensar os corpos como produção sensível e abertura aos possíveis, pois se o real é virtual, o atual é o que acontece. O que estaria mais a serviço do real do que os corpos em seu acontecimento? O corpo se apresenta e se submete, é interessado e receptivo em regime de afetação. Deixaremos de lado os ideais do corpo que constituem o corpo da utilidade, ou o corpo como um apêndice da máquina mental. 
Trataremos o corpo enquanto operação do entre corpos constituindo-se como meio. Um alimento não só sacia a fome, mas constitui a identidade de um povo; um utensílio não é importante somente na medida de sua utilidade prática convencionada, mas também de acordo com o modo como ele aproxima diferentes gerações e constitui subjetividade (BARTHES, 2007). É preciso apenas sair do caráter de previsibilidade e utilidade, abandonar a dimensão estéril da objetificação. A amplificação das relações até o inumano permite o estabelecimento das experiências sensíveis que constituem o corpo potencial. "A paisagem vê" (DELEUZE; GUATTARI, 1997, p. 219), carrega em si afetos que estão longe de poderem ser considerados 'humanos', mas que também não podem ser ignorados enquanto afetos próprios do inumano, dos quais Van Gogh nos deu um mundo de imagens. Vemos o sequestro do corpo como um dos frutos dessa lógica utilitarista e funcionalista que se instaurou sobre as relações, formando um molde binário que generaliza as relações como se só pudessem ocorrer por uma via de mão única: a relação homem-objeto. Mesmo quando homem-objetificado. Mas se o inumano não é o outro de nossa interação humana - aquele Tu que me permite dizer Eu - ele é outrem, ou seja, o outro fora do plano de subjetivação, mas como algo passível de relação. Através desse entrecorpos, as fronteiras entre sujeito e objeto tornam-se cada vez mais indiscerníveis. Por que ignorar um saber fora das epistemes em favor de uma acuidade científica, de uma lógica racional ou mesmo de uma suposta imparcialidade? Sobretudo, "o olhar" é um gesto, por isso não pode ser tocado, no sentido lato da palavra "tocar". O gesto de olhar se assemelha ao gesto dançado do bailarino, por sua constituição sígnica fugidia.

Podemos dizer: a dança, por si própria não significa nada. O gesto dançado, a menos que tenha sido concebido (codificado) para apresentar certa significação precisa, não quer dizer nenhum sentido em que a linguagem articulada poderia traduzir de maneira fiel e exaustiva. O gesto é gratuito, transporta e guarda para si o mistério do seu sentido e da sua fruição (GIL, 2001, p. 103).

Determinados movimentos dos olhos e determinados ângulos e expressões faciais, podem ter significação própria dada por alguma pessoa ou grupo de pessoas, mas no geral seu significado é múltiplo e enigmático, apresentando-se de forma única para cada pessoa. Para Deleuze e Guattari (1997, p. 215) “algo só é uma obra de arte se, como diz o pintor chinês, guarda vazios suficientes para permitir que neles saltem cavalos".

Dos múltiplos sentidos que podem ser atribuídos ao vazio, de qual estamos tratando? Da potência de afecção e de recriação. Se a forma traz a utilidade, o vazio traz o valor, como o diz o passo 11 do TAO. A arte propaga signos que surpreendem até o próprio artista. Mas artistas então somos todos nós que, no simples ato de nos deparar com arte, (re)criamos a arte. Em alguns casos, reconhecemos a arte antes que alguém a denomine, como na fotografia, em cenas do dia a dia, pequenos fragmentos assignificantes que nos afetam. Uma coreografia, por exemplo, é um conjunto de signos plásticos que se compõem e produzem afetos. Dentre os movimentos que exercemos cotidianamente podemos extrair gestos que se exprimem no âmbito de uma medialidade pura sem nenhuma finalidade e que emitem signos e comunicam. A coreógrafa brasileira Carmem Luz, apresentou no teatro Cacilda Becker (Panorama de Dança Contemporanea 2000), como desdobramento de seu trabalho com jovens na comunidade do morro do Andaraí, um trabalho coreográfico, COBERTORES, fazendo dançar a rua e os gestos dos adolescentes habitantes da rua. A vida a céu aberto no gesto da dança. Lindo, impactante e fidedigno.

A criação de um corpo vivo, pulsante, depende do cultivo da sensibilidade, pois existir no mundo é ter e ser corpo, mas, como nos diz Latour (2008, p. 39, online) "O corpo é, portanto, não a morada provisória de algo de superior - uma alma imortal, o universal, o pensamento - mas aquilo que deixa uma trajectória dinâmica através da qual aprendemos a registrar e a ser sensíveis àquilo de que é feito o mundo". As relações de sentido estabelecidas tanto pelo olhar quanto pela dança que os tornam, inclusive, meios de comunicabilidade, são traçadas de forma a obter significações muito específicas e, ao mesmo tempo, plurais. O gesto, a dança e "o olhar" compõem blocos de sensação, "mesmo o vazio é uma sensação, toda sensação se compõe com o vazio, compondo-se consigo, tudo se mantém sobre a terra e no ar, e conserva o vazio, se conserva no vazio conservando-se a si mesmo" (DELEUZE; GUATTARI, 1997, p. 215). O vazio é o que constitui a relação, e a arte acontece na ética da relação. Composição. A ética de adentrar outro "pequeno universo" criando significações muito nossas e valorizando algo que surge ali. Esse adentrar deve acontecer com os olhos e poros bem abertos e "pisando devagar", ou seja, com respeito ao espaço do outro. Essa é a ética da relação. Da mesma forma como não tocamos o gesto de olhar, não tocamos o movimento, tocamos o corpo, o braço, os pés, mas o movimento só é tocado por outro movimento, o movimento só se finda em outro movimento. Ou melhor, não se finda, reverbera, criando novos movimentos que, de certa forma, são extensões infinitas do movimento "inicial". Gil (2001, p. 107) sustenta que o movimento da dança é um movimento infinito. O movimento é muito aerado para ser esquadrinhado por perspectivas biológicas que se apresentem como uma solução definitiva para sua análise. O vazio que circunda o movimento e estabelece a relação entre espaço e corpo também precisa ser considerado na compreensão (não apreensão) do movimento. Tal vazio é característico da relação que se dá no "entre corpos", de um vazio que se constitui com a matéria móvel que é o corpo.

O movimento trabalha constituições distintas, que podem ser observadas na dança, no teatro, em um desfile de moda. Não é apenas a produção de um corpo, mas a produção de uma relação entre corpos e espacialidades, ou seja, tal produção é mútua e simultânea. O bailarino, por exemplo, necessita de referências espaciais para executar o seu movimento, precisa ter o conhecimento do espaço que o cerca e a liberdade de explorá-lo de forma única. A beleza de um movimento depende da sensibilidade do bailarino, da capacidade de utilizar 
as características físicas de seu corpo (peso, força muscular, flexibilidade) como propulsão para os gestos que compõem o mosaico sígnico que concerne à coreografia. Para executar os movimentos com plasticidade, o bailarino necessita desenvolver seu corpo de forma a aguçar sua sensibilidade e criar um corpo-suporte para as exigências da dança. $\mathrm{O}$ que se busca não é o máximo do desenvolvimento muscular, mas aumentar a potência do corpo de forma natural, fazer com que este corpo possa realizar os mais diversos movimentos e em diversas variações rítmicas. Em seu processo de treinamento, como em qualquer atividade que envolva o corpo, o bailarino tem sua estrutura corporal corrigida, moldada ao que é funcional para a execução da dança. Do mesmo modo, o ator também deve preparar o seu corpo de forma similar ao do bailarino. Geralmente, os atores estão comprometidos com certo realismo em seus trabalhos, o que os contrapõe em relação aos bailarinos, que estão mais hábeis a movimentos mais embebidos de afeto. Mesmo com esta ressalva, os atores, em momentos cruciais, são postos à prova, para que deixem de se firmar na técnica e tenham a intuição de agir sem pensar demasiadamente na sua ação. No livro A construção da personagem, Stanislavski (2015) usa a história de um professor e diretor de teatro chamado Tórtsov, e suas aulas em uma escola de teatro em Moscou, para falar de sua técnica. Em certo episódio, o professor leva um acrobata circense à aula de ginástica dos alunos de seu curso e argumenta que, ao acrescentar a "cambalhota" às atividades de aula, estará auxiliando-os na criação dos personagens e "nos grandes momentos de máxima exaltação". Disse-lhes:

O motivo é que a acrobacia ajuda a desenvolver a qualidade da decisão. Para um acrobata seria desastroso demais ficar devaneando logo antes de executar um salto mortal ou qualquer outra proeza de arriscar o pescoço! Nesses momentos não há margem para indecisão. Sem parar para refletir, ele tem de estregar-se nas mãos do acaso e da sua própria habilidade. Tem de saltar, haja o que houver (STANISLAVSKI, 2015, p. 73).

O que o personagem de Stanislavski vê de proveitoso na dança e na acrobacia para o trabalho do ator é a técnica de "padronização do corpo". Ele propõe que o ator se utilize das técnicas de "correção corporal" que os exercícios físicos das duas modalidades trazem consigo. A partir disso, podemos pensar na produção de corpos destinados à execução de determinada função. Mas, se por um lado, essa produção pode ser encarada como forma de docilização dos corpos, como ocorre no cotidiano social, com "métodos que permitem o controle minucioso das operações do corpo, que realizam a sujeição constante de suas forças e lhes impõem uma relação de docilidadeutilidade" (FOUCAULT, 1997, p. 133), por outro lado, pode ser vista como libertação no trajeto de destinação à arte. Podemos pensar em como esses exercícios produzem novas possibilidades de corpo, dão vivacidade a um determinado tipo de sensibilidade, que é sim específico, mas não deixa de se constituir como linha de fuga. Para o desenvolvimento de capacidades corporais que sejam úteis ao movimento artístico, potencializa-se o corpo, am- plifica-se a liberdade do corpo, ao invés de aprisioná-lo. No regime artístico o corpo "aprende" a ser afetado, o que constitui um regime de fuga, pois se desperta o corpo para os afetos. Nesse caso, um "corpo ideal", através de Tórtsov, Stanislavski diz não existir pois, segundo ele

a estrutura humana ideal é coisa que não existe. Tem de ser feita. Com este fim temos primeiro de estudar o corpo e compreender as proporções das suas diversas partes. Os defeitos, uma vez achados, devem ser corrigidos (STANISLAVSKI, 2015, p. 72).

Estes aspectos nos levam a pensar que o bailarino e o ator têm formas diferentes de lidar com os afetos em seus trabalhos, mas ambos necessitam do cultivo de uma dimensão potencial de afeto, que constitui o caráter artístico de suas atividades. A técnica está a serviço do afeto, assim como o corpo está a serviço do gesto. O gesto é a materialidade corpórea do afeto, o que faz o corpo não ter censura. A resposta corporal a certas variações é nítida e não é necessário um corpo extremamente sensível para que isso se faça notar. $\mathrm{O}$ afeto e o gesto se confundem, o gesto afeta e o afeto compõe o gesto, pois são a mesma dimensão em registros distintos. Trata-se não de escolher uma das vias como legítima, mas considerá-las cooriginárias e coexistentes, compondo juntas o corpo intensivo. $\mathrm{O}$ ator trabalha o gesto como produção de figuras do real, o bailarino trabalha o gesto como expressão motora de afeto, já a modelo experimenta o gesto como ficção plástica, podendo variar de um caráter performático (MAC QUEEN, 2011, online) ao modelo de "corpo-cabide" (SAINT LAURENT, 2016, online). O ator preza pela limpeza de seus movimentos, deve exercer um controle extraordinário sobre o corpo para manter-se em um nível de afetabilidade menos passional, sem perder a capacidade de produzir efeitos. O bailarino se concentra mais no corpo e, por meio da sensibilidade, explora a própria potência corpórea a serviço do afeto.

Cada gesto prolonga-se para além de si próprio, numa continuidade tecida pelo movimento da dança. Eis o que parece decisivo: O gesto dançado abre no espaço a dimensão do infinito. Seja qual for o lugar onde se encontra o bailarino, o arabesco que descreve transporta o seu braço ao infinito. As paredes do palco não se constituem como obstáculo, tudo se passa no espaço do corpo do bailarino. Contrariamente ao ator de teatro cujos gestos e palavras reconstroem o espaço e o mundo, o bailarino esburaca o espaço comum abrindo-o até o infinito (GIL, 2001, p. 14).

A modelo tem seu corpo exigido, mas não em relação à potência de movimento. $\mathrm{O}$ seu gesto se caracteriza ou por uma personagem, em que os "excessos" gestuais são permitidos e talvez possam ser uma hipérbole do psiquismo de um grupo, ou uma imagem quase estéril de gestos paupérrimos de afeto. Assim como o ator e o bailarino, a modelo também executa processos de produção de um corpo. No entanto, seu corpo é moldado não no sentido da utilidade e capacidade motora, mas no alcance de um padrão de proporções estéticas muito específicas. O corpo de uma modelo pode ser desenvolvido no sentido motor, mas isto se dá como efeito coadjuvante ao objetivo princi- 
pal, que é um "corpo-vitrine", que em geral se baseia em padrões eurocêntricos. É interessante observar que, assim como os atores, diversas vezes as modelos são advertidas para evitar excesso de gestos. Em contrapartida, em contextos específicos, como certos desfiles e fotos, as modelos devem explorar a própria capacidade expressiva, em alguns casos, se transformando, criando novas imagens e corpos. A modelo é a epítome da imagem, o seu compromisso é emprestar o corpo a uma constituição de personagem imagética, e é necessário um nível de desprendimento da própria imagem para se submeter às diversas e intensas transformações exigidas por esta atividade, pois, a cada trabalho, constrói uma quantidade maior de imagens de si mesma. Tal desenvolvimento pode se refletir na ampliação do repertório de poses que pode executar.

Dadas as semelhanças observadas entre o bailarino, o ator e a modelo, aqui os chamamos de "artistas do corpo". Nessa perspectiva, para obter um maior dinamismo corporal, dinamismo de personagem, eles acabam tendo que neutralizar cada vez mais o corpo e, como nos diz Cunningham (apud GIL, 2001, p. 17) ao falar do bailarino: “o bailarino deve fazer silêncio no seu corpo. Deve suspender nele todo o movimento concreto, sensorial, carnal afim de criar o máximo de intensidade de um outro movimento, na origem da mais vasta possibilidade de criação de formas".

Há necessidade de esconder ao máximo a pessoa do artista para o corpo estar a serviço do gesto do personagem. Porém, há algo da 'identidade' do artista, não uma identidade social, mas sim uma identidade corpórea do campo do singular. Essa singularidade pode ser expressa, de certa forma, pelo que Hubert Godard chama de pré movimento, que seria "essa atitude em relação ao peso, à gravidade, que existe antes mesmo de se iniciar o movimento, pelo simples fato de estarmos em pé" (GODARD, 2002, p. 13). Godard fala de como esse pré-movimento nos permite identificar, quando alguém que conhecemos sobe uma escada, somente pelo barulho impresso através do andar. É um "timbre de movimento", um timbre de corpo que os artistas têm em si e que vai ficando evidente também quando nos familiarizamos com o trabalho do artista. Os artistas do corpo demonstram com clareza a fusão de corpo anatômico e corpo de arte. $\mathrm{O}$ movimento constitui uma produção cinética do corpo-arte, o corpo anatômico se lança em poder de diversas forças variáveis, refutando uma estabilidade que microscopicamente nunca existiu. Dessa forma, não há ausência de movimento, o corpo está sempre em estado de agitação microscópica, mesmo quando aparentemente "em repouso". O que ocorre é uma variação intensiva de movimento. "É antes uma questão de escala de percepção: o repouso (ou primeiro movimento) oferece-se numa macropercepção, ao passo que a micropercepção não encontra, senão, movimento" (GIL, 2001, p. 16).

No teatro, o artista geralmente tem movimentos mais sutis, o que torna as micropercepções de variação algo crucial na busca de uma representação convincente. Um ator prova sua capacidade de representar nas cenas mais intensas de afeto, nas quais deve permitir ser afetado e assim afetar os seus espectadores. Especificamente no teatro, os atores têm um desafio ainda maior, pois a relação que estabelecem é composta por seu próprio corpo, colegas de trabalho, elementos de cena e toda a plateia, que naturalmente também afeta enquanto é afetada. Torna-se notável que o corpo dos afetos sobressaia ao corpo da técnica ou do script, pequenos deslizes não abalam uma atuação visceral e ao mesmo tempo simples, ou seja, intenso em sua microdimensão. Na passarela, a modelo tem a micro dimensão como um grande perigo, ou como o seu diferencial. No campo das micropercepções também estão pequenos gestos que se tornam "marca registrada de uma modelo". É possível também distinguir afetos, às vezes, de uma profissional confiante, que acredita em si mesma e no que veste, ou de uma pessoa que se sente desconfortável ou não acredita no trabalho de quem produziu a roupa. A modelo necessita de compromisso e desprendimento, não basta corresponder aos padrões, ser bela e estar de corpo presente, é preciso estabelecer uma relação de trabalho ética, prazerosa. Estar presente não só na materialidade do corpo, mas na pulsação dos afetos. A atenção aqui direcionada à imagem da modelo, se justifica pelo fato de que, assim como sua indumentária, esta possui um maior nível de variações e múltiplas facetas. Já a imagem do modelo, apesar de um processo de desconstrução, ainda se encontra presa a um conceito de masculinidade que limita os possíveis de sua profissão (VERSACE, 2016, online). É necessário que a ampliação de horizontes no vestuário se intensifique e resulte na ampliação de possíveis para os modelos, um nível de experimentação e de produção criativa maior. $\mathrm{Na}$ dança, da mesma forma, cada variação intensiva importa, cada detalhe é pensado e cuidado, porque cada microalteração é uma coisa nova; pequenas diferenças nos movimentos distinguem um passo do outro, e cada microdiferença constitui o que chamamos anteriormente de identidade do artista. Isso acontece porque a dança opera totalmente em composição estética. Não é a quantidade de movimentos complexos que um bailarino consegue realizar que determinam o seu nível técnico, mas sim o grau de "perfeição" de cada movimento, desde os mais simples, o grau de ajustamento ao que a técnica exige, não por pura técnica, mas porque a técnica trata do detalhe, do cuidado, da delicadeza com que cada passo deve ser executado. Porque, nesse caso, a técnica está a serviço do rigor da expressão. Trata-se de potencializar o corpo, num regime de operação de movimento muito diferente do cotidiano. Trata-se de expandir os possíveis do corpo. Só assim, ele poderá ser canal para a expressão das mais variadas cenas, das cenas que chocam, emocionam, provocam, aliviam, enfim, produzem mundos. É dessa forma que se apresenta um real ficcionado, cheio de graça, de fabulações, que transforma o corpo em arte pura, arte que faz o que Rancière chama de revolução estética: "a abolição de um conjunto ordenado de relações entre o visível e o dizível, entre o saber e a ação, entre a passividade e a atividade" (RANCIÈRE. 2009, p. 25). Tudo isso com uma dose de exagero, como se fosse uma lente de 
aumento, distorção sobre a 'realidade' que faz da arte o meio mais claro que temos de enxergar a nós mesmos, tanto como sujeito quanto como povo.

\section{Referências}

AGAMBEN, G. Meios sem fim: notas sobre a política. Tradução de Davi Pessoa Carneiro. Belo Horizonte: Autêntica, 2015.

BARTHES, R. O império dos signos. Tradução de Leyla Perrone-Moisés. São Paulo: WMF Martins Fontes, 2007.

DEleuZE, G.; GUATTARI, F. Mil Platôs - Capitalismo e Esquizofrenia; vol. 1. Tradução de Aurélio Guerra Neto e Célia Pinto Costa. - Rio de Janeiro: Editora 34, 1995.

DELEUZE, G.; GUATTARI, F. O que é a filosofia?. Tradução de Bento Prado Jr. e Alberto Alonso Munõz. 3. ed. São Paulo: Editora 34, 1997.

FOUCAULT, M. Vigiar e punir: nascimento da prisão. Tradução de Lígia M. Ponde Vassalo. Petrópolis, RJ: Vozes, 1997.

GIL, J. O Movimento Total: o corpo e a dança. Tradução de Miguel Serras Pereira. Lisboa: Relógio D’Água, 2001.

GODARD, H. Gesto e percepção. In: SOTER, S.; PEREIRA, R. (Org.). Lições de dança. Rio de Janeiro: UniverCidade, 2002. v. 3, p. 11-35. Disponível em: <https://docdanca.files.wordpress. com/2013/10/godard-hubert-gesto-e-percepc3a7c3a3o.pdf>. Acesso em: $11 \mathrm{dez} .2016$.

LATOUR, B. Como falar do corpo? A dimensão normativa dos estudos sobre a ciência. In: NUNES, J. A.; ROQUE, R. (Org.). Objectos impuros: experiências em estudos sobre a ciência. Porto: Afrontamento, 2008. p. 39-61. Disponível em: <http:// www.bruno-latour.fr/sites/default/files/downloads/77-BODYNORMATIVE-POR.pdf $>$ Acesso em: 22 out. 2014.

MAC QUEEN, A. Video Alexander McQueen Savage Beauty The Metropolitan Museum of Art, New York. 1 ago. 2011. Disponível em: <https://www.youtube.com/ watch? $\mathrm{v}=\mathrm{P} 13 \mathrm{oZsD}-\mathrm{t} 4 \mathrm{~s}>$. Acesso em: $11 \mathrm{dez} .2016$.

RANCIÈRE, J. O inconsciente estético. Tradução de Mônica Costa Netto. São Paulo: Editora 34, 2009.

SAINT LAURENT, Y. Spring Summer 2017 Full Fashion Show|Exclusive. 27 set. 2016. Disponível em: <https://www. youtube.com/watch? $\mathrm{v}=$ PsTessK0f0w $>$. Acesso em: $13 \mathrm{dez}$. 2016.

STANISLAVSKI, C. A construção da personagem. Tradução de Pontes de Paula Lima. 25. ed. Rio de Janeiro: Civilização Brasileira, 2015.

VERSACE, D. Versace Menswear Fall/Winter 2016-2017. 16 jan. 2016. Disponível em: <https://www.youtube.com/ watch? $v=-M 3 u o M V g S S k>$. Acesso 10/12/2016.

Recebido em: 22 de dezembro de 2016 Aceito em: 30 de junho de 2017 